\title{
NUMERICAL ANALYSIS OF THE BRIDGE ORTHOTROPIC DECK TIME DEPENDENT RESISTANCE
}

Resistance of the stiffened plated orthotropic deck of bridge with ballast bed is affected by the environmental action effects due to unchecked corrosion process of steel bridge deck under ballast bed. Therefore, to observe the behaviour and resistance of those types of steel bridges, the probabilistic nonlinear finite element analysis using adequate sophisticated software is needed. The paper presents results of the parametric numerical analysis of the time dependent resistance of bridge with ballast bed on the orthotropic deck considering corrosion attack using ANSYS software support module PDS. Random variables entering calculations were described by means of parameters of probability density functions according to data determined experimentally. The model takes also into account the geometrical and material nonlinearities of bridge structure including the selected corrosion models.

Keywords: Steel orthotropic plated structures, time-dependent corrosion effects, numerical simulations, time dependent resistance.

\section{Introduction}

Steel bridges with ballast beds lying on the compression orthotropic plate decks are spatial structures with very complicated behaviour. The orthotropic deck of those bridges consists of thinwalled sheets stiffened by the system of longitudinal and transversal stiffeners. Its stress state is significantly influenced by the interaction of global and local buckling, shear-lag and effect of transversal load due to traffic action effects resulting from the deck performance. Moreover, the geometrical and material nonlinearities are necessary to take into account. Accurate prediction of the resistance of stiffened plated elements is a very important task for engineers. Therefore, the extensive work in predicting the compressive resistance of those type of structural elements has been conducted since 1970s. The results of the effort were presented in many papers and works, whose summary can be found e.g. in [1]-[5], and they were introduced into the last edition of Eurocodes [6]. Three types of methods could be normally used to estimate the resistance or stress state of stiffened plate, i.e. the experimental method, analytical method and numerical simulation such as the finite element method employing advanced numerical models [7].

The solution of the stress state of compression and transversally loaded bridge decks in the analytic form is practically impossible. Therefore, simplified procedures based on the assumptions of linear elasticity methods including stress superposition have been preferred and involved into the Eurocodes because of their general simple use. However, those methods are applicable for routine design and they do not provide appropriate outputs convenient for research concerning with the time dependent reliability verification due to e.g. degradation effects. To obtain more accurate results, the numerical simulations should be used.

However, many factors influencing the resistance of the bridge orthotropic deck are random variables even random processes. Therefore an adequate probabilistic model of resistance determination is necessary to develop from the viewpoint of structural reliability assessment due to significant uncertainties of the initial performance, effects of deterioration caused by environmental actions like corrosion and because of stochastic nature of all factors affecting the resistance (geometric parameters and material properties).

It is necessary to notice that numerical calculations based on the finite element method using nonlinear analysis considering both geometrical and material nonlinearities are quite time consuming. An increased interest in application of those types of structures (not only in the bridge engineering) and not sufficiently known way how to determine the actual resistance of the stiffened plate gives the possibility to employ an approach based on the artificial neural network enabling to derive a design formula predicting the resistance of stiffened plates by means of the response surface method using existing experimental data and numerical results.

As mentioned above, the actual bridge resistance could be changed by various factors like degradation of materials due to aggressive environment. In general, deteriorating structures are maintained in accordance with their condition states. Although many quality corrosion protection systems are available at present, due to limited available resources and incorrect maintenance deci-

\footnotetext{
* Josef Vican, Marian Sykora

Faculty of Civil Engineering, University of Zilina, Slovakia, E-mail: vican@fstav.uniza.sk
} 
sions, phenomena of corrosion as the basic and most important degradation effect is significant all the time. Effects of this degradation cause material loss leading to the reduction of structural resistance. Corrosion effects influencing resistance can be obtained by means of structural model based on some corrosion models. Then, the corrosion effects could be expressed in the form of the time variant loss of the resistance. The parametric study of corrosion effects simulation was realized to observe the variation of the bridge deck resistance within the bridge service lifetime resulting from the generalized corrosion of the bridge stiffened deck plate.

A proper consideration and treatment of uncertainties enables a more sophisticated reliability assessment and ensures the quality and reality of the bridge global analysis. The methodology of the probabilistic approach to the bridge orthotropic deck reliability introduced in this paper is a part of the global study related to the remaining lifetime and durability of structures, which is a longterm subject of the research activities of the Department of structures and bridges [8], [9] and [10].

\section{Bridge computational model}

The simulations were performed by means of computational model (see Fig. 1) of the real bridge structure (Fig. 2) using the finite-element package ANSYS, taking into account the nonlinear structural behaviour. The Shell 181 element (four nodded shell element with six degrees of freedom at each node) suitable for large rotation and large deflection of nonlinear applications was chosen Moreover, the model should include the same boundary conditions as those in the real structure and therefore should also respect the actual material properties and relevant initial imperfections.

The isotropic nonlinear plastic material behaviour was modelled using the von Misses yield criterion coupled with an isotropic work hardening assumption and a multi-linear approximation of the stress-strain curve. Due to absence of measured initial imper- fections, the standard equivalent geometrical initial imperfection in the form of sinusoidal surface was incorporated into the computational model. The transverse displacement fields of imperfect plates are normally represented by a double Fourier series. For ratios of plate dimensions usually used on the bridge decks, the following equation was applied to take into account the initial imperfections

$$
w_{0}=f_{0} \sin (\pi x / a) \sin (\pi x / b),
$$

where $f_{0}$ is value of initial bow, $a$ is the plate length (between adjacent cross-beams) and $b$ is the plate width (between main girders) respectively. The amplitude of the longitudinal stiffener initial bow was considered by the value of $a / 400$ in accordance with [6] and the initial bow of the deck sheet in transversal direction between longitudinal stiffeners was given in the form of "hungry horse" with the amplitude $b_{0} / 200$, where $b_{0}$ is the axes distance of the adjacent longitudinal stiffeners (see Figs. 1 and 2).

Two numerical finite calculation models were created. Firstly, the deterministic model was developed. Secondly, the probabilistic model was created using deterministic one and software support module PDS (Probabilistic Design System) allowing for direct connection between FEM analysis and methods of the probability analysis. Based on the parameters of material characteristics as well as other random variable input values and their statistical models, PDS module enables to generate files of random variables and to calculate required probabilities. Basic input random variable characteristics were obtained from experimental measurements and can be found in [11].

Random character of the bridge geometric parameters (see Fig. 2) was considered in accordance with the Gaussian random process and the log-normal distribution was applied in the case of material characteristics (modulus of elasticity and yield strength). Random variables were described by means of parameters of probability density distribution according to data determined experimen-
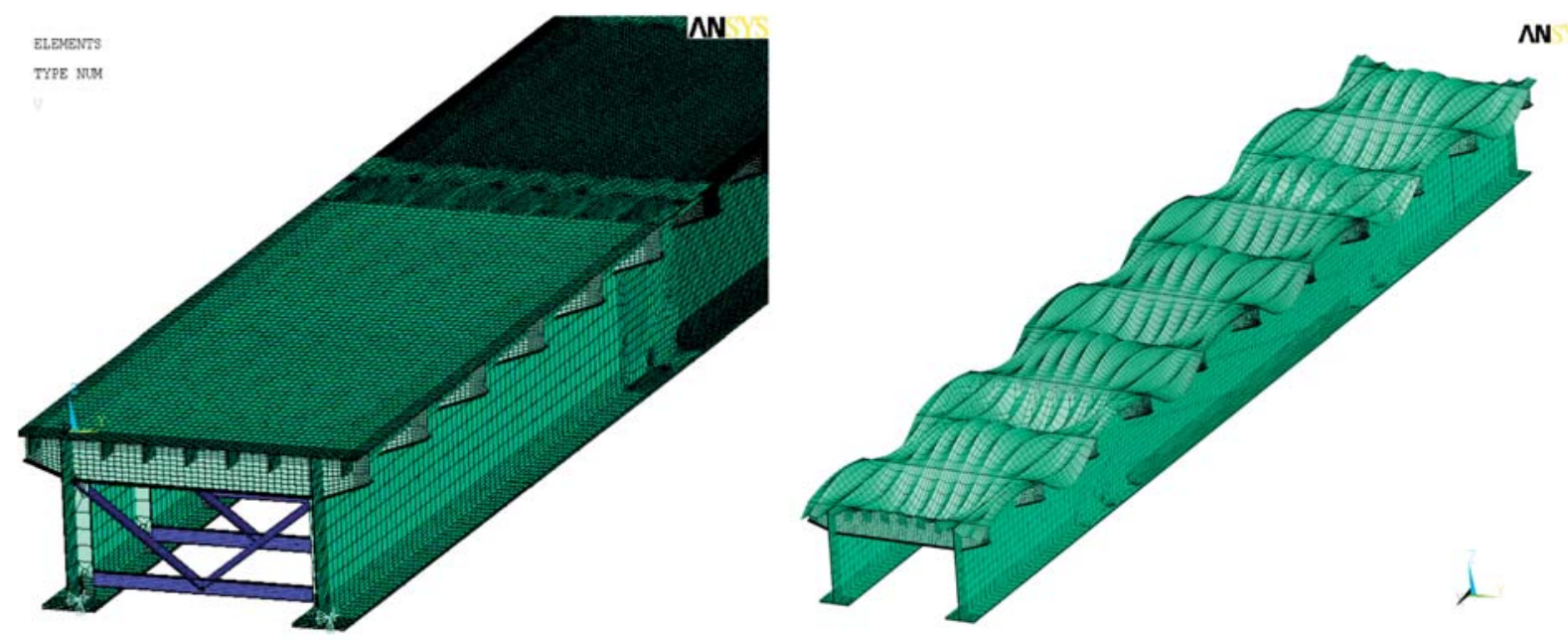

Fig. 1 Structural model of bridge with orthotropic plate deck - detail of finite element meshing and shape of initial imperfections (100 times multiplied) 
tally. The traffic action on bridge was modelled by means of idealised uniformly distributed load representing the relevant load model of railway traffic action [12].

The developed models were calibrated using the results of experimental analysis accenting the structural behaviour of the real bridge shown in Fig. 2. The calculations were carried out using LHS simulation method for 40 steps of the data dispersion. The nonlinear calculation ran in every step determining random output parameters in the form of stresses and deformations of girder upper flanges in experimentally measured places (see Fig. 2). Comparative analysis of the results proved the very good agreement of the measured outputs with the calculation results obtained by means of the above described probabilistic numerical model.

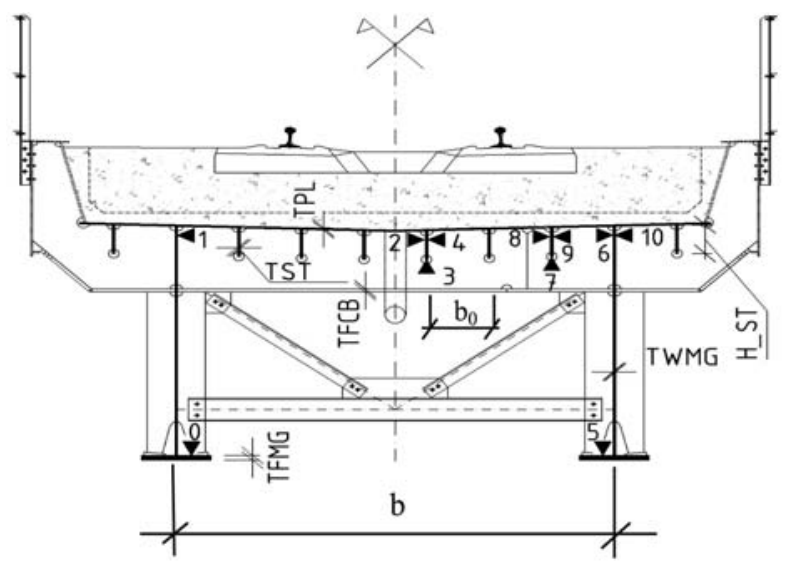

Fig. 2 Bridge cross-section with designated measured places and geometrical parameters

\section{Corrosion degradation modelling}

Corrosion of the bridge plated deck due to environmental conditions was taken into account. A lot of effort was done to evolve appropriate analytical models of corrosion mainly through extrapolation procedures processing the results of in-situ measurements. Many factors including the corrosion protection system and various operational parameters are influencing the corrosion rate and due to this complexity of the problem, it is difficult to express the time dependent loss of material. Although, several research long-time programmes were realized in the past and many factors influencing degradation process are known, models of corrosion loss in time are more or less simplified. Conventional models consider the constant measure of corrosion loss in time, which is leading to almost linear dependence of material loss on time. However, experimental measurements proved that nonlinear models are more appropriate. Because of random variable character of many parameters entering corrosion process, the probability theory and mathematic statistics should be the most appropriate approaches to describe it. At present, several corrosion models are known, which could be generally used for analysis of the corrosion influence on the structural reliability.

However, these corrosion models were developed for structural steel with general corrosion protection. Insulation system used for actual bridge structure under ballast bed is based on the epoxy resins extra resistant against the environmental actions. The passive stadium of the corrosion process, where insulation system is resisting to environmental actions, is unknown. Therefore, due to absence of the above mentioned actual corrosion model of the structural steel under ballast bed, the known corrosion prediction models of structural steel degradation were used for the corrosion modelling. The model of Akgul-Frangopol [13] was used to simulate the corrosion process under insulation of the bridge deck and the model of Qin-Cui [14] was applied for the modelling of the corrosion process on the lower part of the bridge deck. The corrosion losses were determined using relations expressing mean values and standard deviations. In the case of the Frangopol model, the following equations were used

$$
\begin{aligned}
& \mu_{\text {dcorr }}=0.03207 t^{0.5}, \\
& \sigma_{\text {dcorr }}=0.00289 t^{0.045}
\end{aligned}
$$

and in the case of the Qin-Cui model, the following relations were applied

$$
\begin{aligned}
& \mu_{d c o r r}=1.67\left[1-\exp (-t / 9.15)^{1.97}\right], \\
& \sigma_{d c o r r}=0.0674\left[1-\exp (-t / 0.181)^{0.0294}\right],
\end{aligned}
$$

where $t$ is time in years, $\mu_{d c o r r}$ and $\sigma_{d c o r r}$ are the mean value and standard deviation of the corrosion lost.

Corrosion effects was taken into account by means of thickness reduction $d_{c o r r}$ calculated according to the above mentioned probability models using following relation

$$
t_{p l, r e d}=t_{p l}-d_{c o r r}
$$

where $t_{p l}$ is the plate thickness without corrosion effects.

For practical use, such approach was applied in which time variant problem of corrosion influence on the structural resistance is solved by means of time invariant problem in several discrete time points with resulting reduced cross-sectional characteristics due to corrosion effects.

\section{Parametric study of the corrosion effects on the bridge deck resistance}

The resulting bridge deck resistance due to corrosion effects depends on several factors. Firstly, it is necessary to observe the influence of slenderness of the bridge plate and longitudinal stiffeners creating the bridge deck. Moreover, the effect of the material mechanical properties plays also an important role. The effect 
of the global bridge geometric parameters and the bridge arrangement are other equally important factors, which are manifested mainly in the form of stress distribution over the bridge crosssection due to influence of the shear-lag and plate buckling.

To determine the impact of time-varying corrosion effects on the bridge deck resistance, a parametric study was performed in which the variation of slenderness of steel plate was considered in range from 30 to 45 in increments of 5 and slenderness of longitudinal stiffeners varied from 30 to 60 in increments of 10 . Thus, the study consisted of 16 types of bridge structures with plated orthotropic decks. The impact of changes in the quality of the material due to a considerable amount of study parameters was not considered and, therefore, only one type of material i.e. steel S355 was used in the study. The input geometric parameters of the parametric study are presented in Table 1 , where $t_{p l}$ means the thickness of the deck plate, $\beta_{p}$ is the slenderness of the deck plate $\mathrm{a}$ is the span of the longitudinal stiffener, $b_{0}$ is the axes distance of the adjacent longitudinal stiffeners, $h_{s t}$ is the depth of the longitudinal stiffener, $t_{s t}$ is the thickness of the longitudinal stiffener and $\lambda_{s t}$ is the slenderness of the longitudinal stiffener. Details of the study input parameters are presented in [8]. The above described parameters were considered as the random variables. The crossbeams of the bridge deck were modelled in the same way for all observed cases as $\perp$ cross-section with the web parameters of $14.30 \times 550.00 \mathrm{~mm}$ and bottom flange parameters of $15.60 \times$ $200 \mathrm{~mm}$. The main bridge girders were also considered in the same way for all cases with the web parameters of $14.30 \times 1900 \mathrm{~mm}$ and the bottom flange parameters of $50.10 \times 700 \mathrm{~mm}$.

Input geometric parameters of the parametric study

Table 1

\begin{tabular}{|c|c|c|c|c|c|c|c|}
\hline $\begin{array}{c}\text { Case } \\
\text { No. }\end{array}$ & $\begin{array}{c}t_{p l} \\
{[\mathrm{~mm}]}\end{array}$ & $\beta_{p}$ & $\begin{array}{c}a \\
{[\mathrm{~m}]}\end{array}$ & $\begin{array}{c}b_{0} \\
{[\mathrm{~m}]}\end{array}$ & $\begin{array}{c}h_{s t} \\
{[\mathrm{~m}]}\end{array}$ & $\begin{array}{c}t_{s t} \\
{[\mathrm{~m}]}\end{array}$ & $\lambda_{s t}$ \\
\hline 1 & 14.00 & 30.00 & 1.925 & 0.420 & 0.200 & 0.020 & 30.00 \\
\hline 2 & 14.00 & 35.00 & 1.874 & 0.490 & 0.200 & 0.020 & 30.00 \\
\hline 3 & 14.00 & 40.00 & 1.824 & 0.560 & 0.200 & 0.020 & 30.00 \\
\hline 4 & 14.00 & 45.00 & 1.777 & 0.630 & 0.200 & 0.020 & 30.00 \\
\hline 5 & 14.00 & 30.00 & 2.567 & 0.420 & 0.200 & 0.020 & 40.00 \\
\hline 6 & 14.00 & 35.00 & 2.499 & 0.490 & 0.200 & 0.020 & 40.00 \\
\hline 7 & 14.00 & 40.00 & 2.432 & 0.560 & 0.200 & 0.020 & 40.00 \\
\hline 8 & 14.00 & 45.00 & 2.369 & 0.630 & 0.200 & 0.020 & 40.00 \\
\hline 9 & 14.00 & 30.00 & 3.209 & 0.420 & 0.200 & 0.020 & 50.00 \\
\hline 10 & 14.00 & 35.00 & 3.123 & 0.490 & 0.200 & 0.020 & 50.00 \\
\hline 11 & 14.00 & 40.00 & 3.041 & 0.560 & 0.200 & 0.020 & 50.00 \\
\hline 12 & 14.00 & 45.00 & 2.962 & 0.630 & 0.200 & 0.020 & 50.00 \\
\hline 13 & 14.00 & 30.00 & 3.850 & 0.420 & 0.200 & 0.020 & 60.00 \\
\hline 14 & 14.00 & 35.00 & 3.748 & 0.490 & 0.200 & 0.020 & 60.00 \\
\hline 15 & 14.00 & 40.00 & 3.649 & 0.560 & 0.200 & 0.020 & 60.00 \\
\hline 16 & 14.00 & 45.00 & 3.554 & 0.630 & 0.200 & 0.020 & 60.00 \\
\hline
\end{tabular}

The resistance of the bridge structure was determined using incremental analysis in which the limit state was defined by the total structural collapse. In order to determine the collapse load in a more accurate way, the gradually increasing load with the defined time step of $1 / 200$ was applied until structural failure. The time-dependent resistance of the structure was calculated within the structural design lifetime of 100 years for both above mentioned models of corrosion losses. Therefore, the structural resistance was determined at different time points with the time step of 5 years for the structural age until 25 years and then the time step was adjusted to 25 years. It was considered that the corrosion is affecting on the lower and upper part of the bridge deck respecting the assumption not perfectly functional isolation of the bridge deck under ballast bed for the whole design lifetime of the structure.

Results of the parametric study were presented in the form of curves expressing the decrease of the time dependent structural resistance in the measured points of the observed structure. The curves were determined as the ratio of the structural resistance including the corrosion effects at the bridge lifetime of 100 years to the resistance without the influence of the corrosion losses at the beginning of the bridge lifetime. The resistance was either defined in accordance with the elastic limit state due to attaining the yield strength in the most loaded point of bridge deck, or as the plastic limit state by means of achieving the plastic strain $2 \varepsilon_{y}$ ( $\varepsilon_{y}$ means the strain corresponding to the yield strength) in the most loaded point of the bridge deck. Results of the structural resistance decreases measured in selected relevant points of structure (see Fig. 2) are presented in Figs. 3 - 5.

The above described approach to determine the resistance decrease is suitable for elastic phase of the bridge loading. This approach is not accurate in the elastic-plastic stage of the bridge behaviour due to elastic-plastic stress redistribution over the bridge cross-section. Therefore, the more accurate approach how to estimate the degradation effect of the corrosion process on the bridge deck resistance is determining the limit load corresponding to attaining the bridge deck limit state. Then the ratio of this load to the limit load at the beginning of bridge lifetime could also give the answer related to the resistance loss due to corrosion effects. Results of this approach are presented in Fig. 6.

\section{Conclusions}

From the comparison presented in Figs. 3-5, the decrease about $12.5 \%$ of resistance is evident due to the corrosion attack on the bridge deck in the case of bridges with longitudinal stiffeners having slenderness less than 40 (cases 1-10). Concurrently, the resistance loss is successively decreasing to $18 \%$ with the slenderness increasing. In time period till 25 years of bridge lifetime, the significant dynamic of the corrosion process with nonlinear courses is visible, that is connected with the development of the initial and transitive phase of the corrosion process.

The resistance decrease is slowing after stabilisation of corrosion process and creating the layers of corrosion product with pro- 

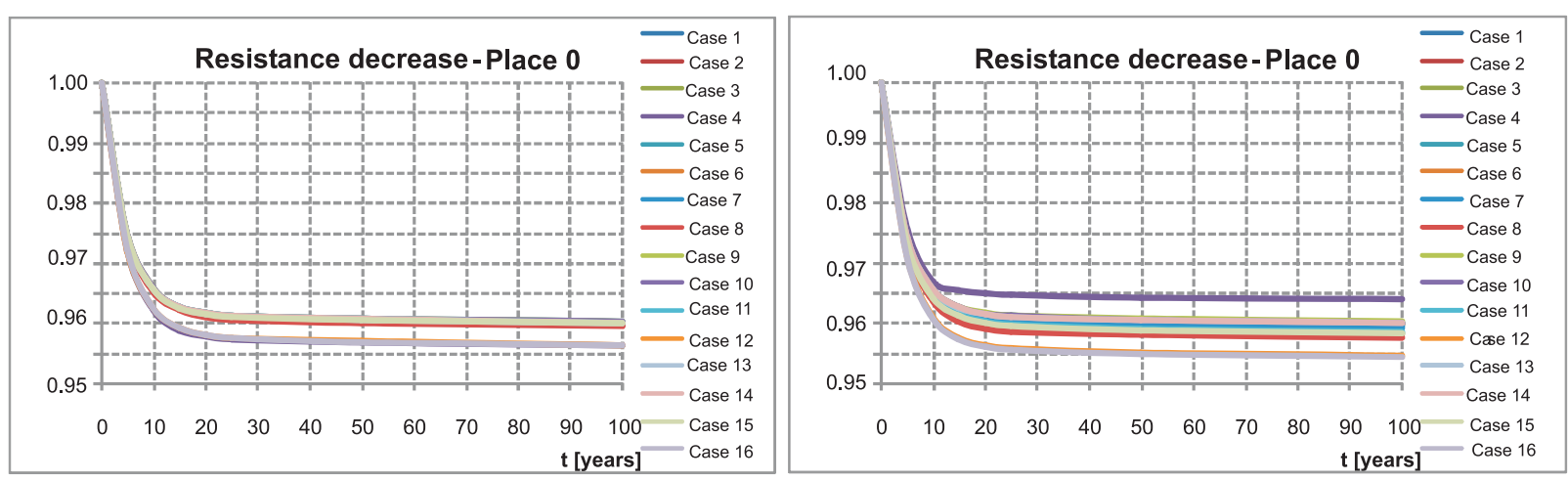

Fig. 3 Time dependent structural resistance decrease in the observed point 0 expressed in the form of limit state stress ratio (left - elastic limit state, right - plastic limit state defined by achieving $2 \varepsilon_{y}$ in the most loaded point)
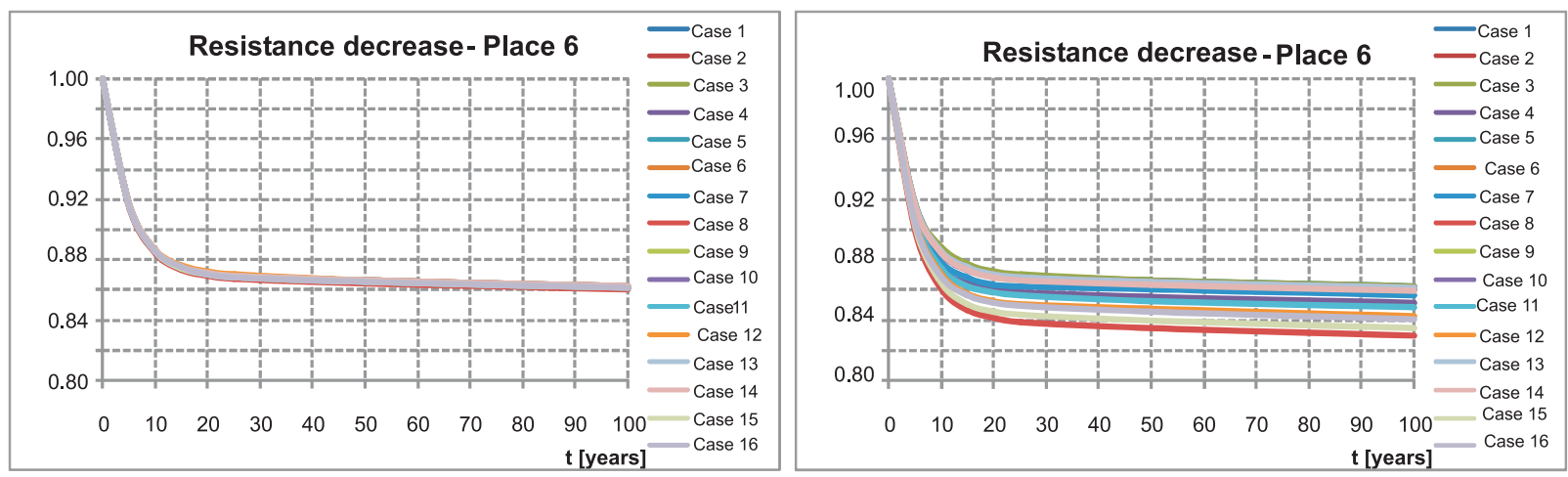

Fig. 4 Time dependent structural resistance decrease in the observed point 6 expressed in the form of limit state stress ratio (left - elastic limit state, right - plastic limit state defined by achieving $2 \varepsilon_{y}$ in the most loaded point)
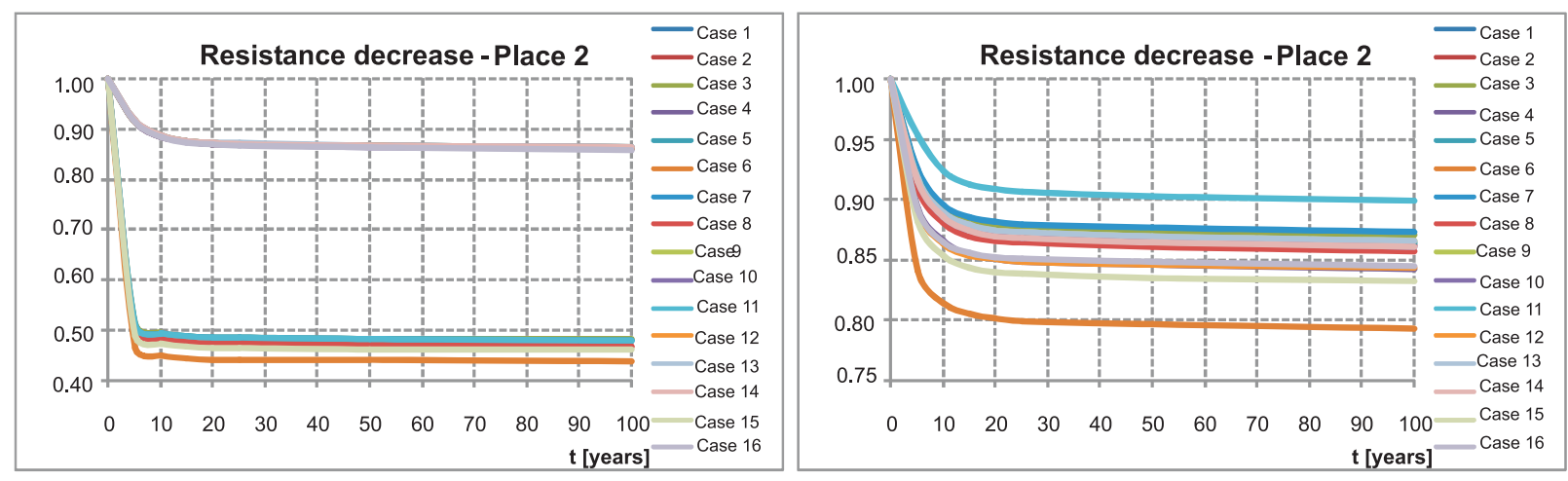

Fig. 5 Time dependent structural resistance decrease in the observed point 2 expressed in the form of limit state stress ratio (left - elastic limit state, right - plastic limit state defined by achieving $2 \varepsilon_{y}$ in the most loaded point)

tective effect, so that the process is then approximating to a linear course. The equal conclusions are evident from the comparison of time dependent resistance decrease by means of the limit loads presented in Fig. 6.

\section{Acknowledgement}

This work was supported by the Slovak Research and Development Agency under contract No. APVV-0106-11 and by Research Project No. 1/0364/12 of Slovak Grant Agency. 


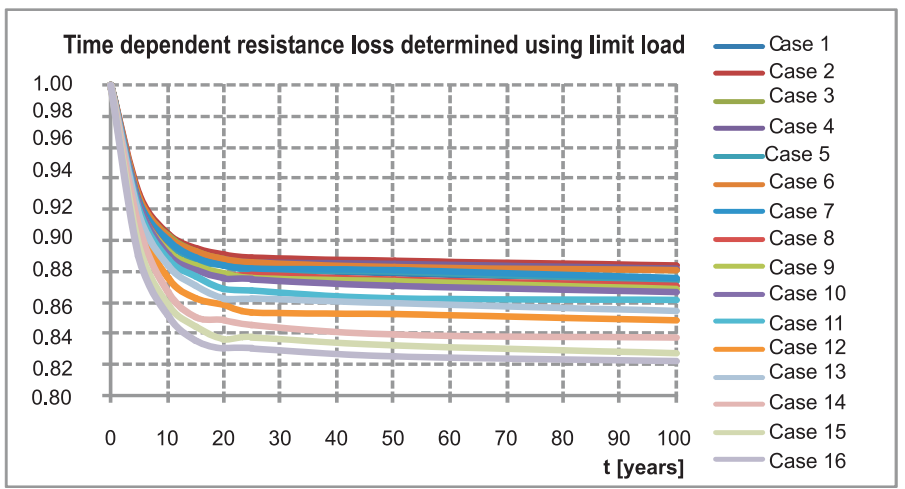

Fig. 6 Time dependent structural resistance decrease in the form of limit state load ratio

\section{References}

[1] MAQUOI, R., MASSONET, CH.: Theorie non lineare de la resistance postcritique des grandes poutres en caisson raidies. Memoires de I AIPC, vol. 31-II, Zurich 1971.

[2] BALAZ, I., DJUBEK, J.: Ultimate Strength of Compression Orthotropic Plate. J. of Building Engineering, vol. 26, 1978, No. 4, pp. 283-301.

[3] SKALOUD, M.: Design of Plates and webs of Steel Structures, Academia Praha, 1988.

[4] SERTLER, H., VICAN, J.: The Real Behaviour of Steel Railway Bridges (in Czech). Zilina, ES VSDS, 1995.

[5] KVOCAK, V.: Stability of Plated Flanges. Monograph, TU Kosice, 2012.

[6] EN 1993-1-5 Eurocode 3: Design of Steel Structures. Part: 1-5: Plated structural elements, CEN Brussels, 2003.

[7] KALA, Z., KALA, J.: Resistance of Plate Girders under Combined Bending and Shear, Latest Trends on Engineering Mechanics Structures, Engineering Geology, Athens : World scientific and engineering acad. and soc. 2010, pp. 166-171, ISBN 978-960-474203-5.

[8] VICAN, J., SYKORA, M.: Design of Compression Members for Durability, Communications - Scientific letters of the University of Zilina, vol. 11, No. 4, 2009, pp. 9-14, ISSN 1335-4205.

[9] VICAN, J., GOCAL, J., MELIS, B., KOTES, P., KOTULA, P.: Real behaviour and Remaining Lifetime of Bridge Structures, Communications - Scientific Letters of the University of Zilina, vol. 10, No. 2, 2008, pp. 30-37, ISSN 1335-4205.

[10] DURATNA, P., BOUCHAIR, A., BUJNAK, J.: Analysis of the Behaviour of Steel-concrete Composite Truss, Communications Scientific Letters of the University of Zilina, vol. 13, No. 4, 2011, pp. 46-50, ISSN 1335-4205.

[11] SYKORA, M.: The Remaining Lifetime of Bridge Decks with Ballast Beds. PhD thesis. University of Zilina, 2010.

[12] STN EN 1991-2 Eurocode 1: Actions on Structures. Part 2: Traffic actions on bridges. SUTN Bratislava 2006.

[13] AKGUL, F., FRANGOPOL, D. M.: Lifetime Performance Analysis of Existing Steel Girder Bridge Superstructures. J. of Structural Engineering, vol. 130, No. 12, pp. 1875-1888.

[14] QIN S., CUI W.: Effect of Corrosion Models on the Time-dependent Reliability of Steel Plated Elements, Marine Structures, Elsevier, 2003. 